\title{
IDENTIDAD CICLICA DE TRES TRISTES TIGRES
}

\author{
POR
}

\author{
ISABEL ALVAREZ-BORLAND \\ College of the Holy Cross
}

"Sé lo que TTT no es. No es una novela, no es una colección de cuentos, no es un libro-poema, como Paradiso, por ejemplo. Es tal vez, un libro de fragmentos en busca de la unidad, como los eslabones quieren $-\mathrm{y}$ tienen que-. componerse en cadena para ser algo más que un grupo de eslabones. ¿Eureka! Ya lo tengo: TTT es un libro libre: El genio fuera de la botella". Esa fue la respuesta dada por Cabrera Infante cuando, en una entrevista reciente, le preguntaba como categorizaba él la estructura de Tres tristes tigres. La respuesta es importante y a la vez sugestiva si se considera que uno de los principales obstáculos que presenta la lectura de T'TT estriba en los juicios de la crítica, que se acerca al libro con la misma actitud que promueve toda novela tradicional. Hasta ahora, los artículos y estudios más fructíferos sobre TTT han sido aquellos que se concentran en las cualidades orales y en problemas lingüísticos de la obra ${ }^{2}$. Sin embargo, aunque las investigaciones lingüústicas han sido muy valiosas para la comprensión de la obra, las indagaciones sobre la estructura 'caótica' del texto han sido poco satisfactorias.

El desacierto en enjuiciar la estructura de TTT se debe en parte al hecho de que ninguno de sus críticos ha destacado, con la debida precisión, la importante relación que la obra posee con otros géneros en la obra del autor, como el cuento y la viñeta. La variedad genérica que se observa dentro de este texto justifica otro enfoque del libro, ya que el acercamiento novelístico deja muchos problemas sin resolver.

${ }^{1}$ Entrevista personal con Guillermo Cabrera Infante, IIispamérica, (1982).

2 Emir Rodríguez Monegal, "Estructura y significaciones de Thes tristes ligres", en $G$. Cabrera Infante (Madrid: Fundamentos, 1974) 81-129; A. Bensoussan, "Entrevista con Cabrera Infante", Insula, No. 286 (sept., 1970): 4; Nicolás Rosa, "Cabrera Infante: una patologia del lenguaje", en Critica y significación (Buenos Aires: Galerna, 1970) 175225; Jose Schraibman, "Cabrera Infante iras la búsqueda del lenguaje”, Insula, No. 286 (sept., 1970): 1, 15-16. Sharon Magnarelli, "The Writer in TT"T", en The Analysis of Hispanic Texts, (Jamaica, Bilingual Press, 1976) 300-20; Josefina Ludmer, "TTT?. Ordenes literarios y jerarquías sociales", Revista Iberoamericana, 45 (1979): 493-512; Stephanie Merrim, "Language in Thes tristes tigres", Latin American Literary Review, (Spring/Summer 1980): 96-118. 
Estos problemas se hacen evidentes si se considera que una de las relaciones básicas de toda novela la constituye la influencia recíproca entre el personaje y los acontecimientos. Una rápida ojeada a las partes consecutivas de $T T T$, no sólo hace constar su fragmentada estructura externa, sino también la dificultad para encontrar en el texto dos de los elementos indispensables al género novelístico: una trama central, así como personajes que se desarrollen y cambien en relación con la misma.

Si se construye un índice cronológico de todas las partes del texto y se compara con el verdadero Indice de TTT, se podrá apreciar que el índice que aparece en el texto no incluye ninguna de las narraciones de "Ella cantaba boleros" narradas por Códac, ni incluye tampoco las viñetas psiquiátricas narradas por Laura ${ }^{3}$. Mediante esta comparación se puede determinar que el Indice al tera el carácter del texto y es traicionero ${ }^{9}$, ya que sirve más para perder al lector que para orientarlo. De la misma manera, se debe notar que el uso de once narradores en primera persona provee una unidad engañosa, dado que aunque ofrece cierta uniformidad, al mismo tiempo contribuye a la fragmentación de la trama y a la coexistencia de varias historias que nunca llegan a entrecruzarse.

Sin embargo, si se presta atención a los cinco narradores más importantes del texto: Códac, Cué, Silvestre, Laura y Eribó se podrá apreciar que existe cierta unidad narrativa dentro del libro. A continuación se ofrecerá un esquema general de las variadas 'tramas' que se encuentran en $T T T$, las cuales serán la base de nuestra lectura del texto:

I. Núcleo Primero: narradores varios

A. "Prólogo": presentaciones del "emci" (viñeta)

B. "Los debutantes":

1. Grupo femenino

\&. narración infantil: Laura (cuento)

b. carta de Delia Docc (viñeta)

c. conversación telefónica de Beba (viñeta)

d. conversación de Magalena (viñeta)

2. Grupo masculino

a. cuento de Silvestre

b. cuento de Cué

c. cuento de Eribó

\footnotetext{
${ }^{3}$ Rodríguez Monegal fue el primero en scñalar la identidad de Laura basándose en la opinión del mismo autor, 126.

4 Carta recibida de Guillermo Cabrera Infante, marzo 31 de 1979 . En dicha carta, Cabrera Infante indica que el "Indice" de Un oficio del siglo $X X$ estaba destinado a confundir al lector. Esta misma estrategia se repite en TTT.
} 
II. Núcleo Segundo: Códac

A. "Ella cantaba boleros": No. 1-No. 8 (cuento).

B. Serie de Bustrófedon (memorias).

1. "Rompecabezas".

2. "La muerte de Trotsky referida por varios escritores cubanos, años después o antes".

3. "Algunas revelaciones".

III. Núcleo Tercero: Eribó

A. cuento (véase "Los debutantes").

B. "Seseribó" (cuento).

IV. Núcleo Cuarto: Cué

A. cuento (véase "Los debutantes").

B. "La casa de los espejos" (cuento).

\section{Núcleo Quinto: Silvestre}

A. cuento (véase "Los debutantes").

B. "Bachata" (glosa al texto).

VI. Núcleo Sexto: Mr. Campbell

A. "Historia de un bastón y algunos reparos de Mrs. Campbell". Traducción de Silvestre (cuento).

B. "El cuento de un bastón seguido de vaya que correcciones de la Sra. de Campbell". Traducción de Rine Leal (cuento).

\section{Núcleo Séptimo: Laura}

A. narración infantil (véase "Los debutantes").

B. conversaciones con el psiquiatra (viñetas No. 1-No. 11).

\section{Núcleo Octavo: Mujer anónima}

A. Epilogo: (viñeta).

Los ocho núcleos que se acaban de delinear están relacionados muy sutilmente. Estos no desarrollan una acción central que los une, sino que se relacionan unos con otros a través de paralelas temáticas, ciertos procesos lingüísticos similares, así como mediante palabras y expresiones recurrentes. Es curioso notar que estas 'unidades de acción' pueden existir independientemente, es decir que estas se pueden leer como relatos cortos o viñetas. TTT no posee una trama central ni posee el desarrollo causal que son parte integral de toda novela tradicional.

Ligado a la ausencia de una trama central, se encuentra el problema de los personajes. En TTT, los personajes aparecen y desaparecen en forma abrupta, 
y raramente se puede seguir sus movimientos o desarrollo emocional. El extenso uso de la viñeta y el cuento contribuyen a la fragmentación del personaje y a su falta de diferenciación. Si La Estrella, Bustrófedon y Laura son inconfundibles, Silvestre, Cué y Códac parecen fundirse y confundirse en sus acciones y opiniones. De la misma manera, las múltiples mujeres que aparecen en el texto poseen todas rasgos muy similares que hacen imposible su individualización. A estos rasgos compartidos también se podría añadir la distancia textual y cronológica que separa los relatos narrados por los mismos personajes (eg. el cuento de "Los debutantes" narra un episodio de la infancia de Silvestre mientras que la narración de "Bachata" es narrada por un Silvestre ya maduro). Como en el caso de la trama, se observa que existe en el texto un rechazo de caracterización de los diferentes personajes, rechazo que resulta llamativo al omitir todo adentramiento psicológico que se ofrece al autor mediante el uso de la primera persona narrativa. Por otra parte, el verdadero elemento novelesco en TTT es la realidad hacia la que todos los relatos de este libro apuntan, es decir, la creación de un ambiente específico y de una época específica. No se trata aquí de una minuciosa reconstrucción histórica sino más bien de reproducir las condiciones de la vida nocturna en La Habana de los años 1958-1959. La ciudad y su farándula nocturna son recreadas a través de todas las páginas del texto, a veces de una manera realista y exacta y otras de una manera más bien abstracta e intelectualizada.

Todos los núcleos de TTT poseen una doble estructura en la que se elabora primero el ambiente de la noche urbana y después la aventura en cuestión. Sin embargo, la presencia de un solo factor novelesco no justifica del todo que se considere al libro como novela. Por tal razón, este estudio propone un acercamiento genérico que contribuya a una mejor y más completa comprensión del complicado texto. La base de esta lectura alternativa se encuentra en los perceptivos estudios de Forrest L. Ingram y su teoría del 'ciclo de relatos' (short story cycle).

El estudio, provocativo de por sí, se titula Representative Short Story Cycles of the Twentieth Century ${ }^{5}$. En el mismo, Ingram estudia y describe no sólo la extensión, sino también la versatilidad de este género cuyos límites serian, en un extremo, una colección de cuentos sueltos publicados bajo una misma cubierta, mientras que el otro extremo sería la unidad evolutiva y causal que representa una novela.

Un ciclo de relatos debe poseer una unidad que es intrínseca y extrínseca a la vez. Este fenómeno se basa en los patrones estéticos que gobiernan los ciclos de relatos, o sea lo que Ingram llama el principio del "recurrent development" (desarrollo y repetición):

${ }^{5}$ Forrest L. Ingram, Representative Short Story Cycles of the Twentieth Century (Tho Hague: Mouton Co., 1971). 
It consists, most simply, in the repetition of a previously used element (motif? phrase, character, etc.) in a modified form or context, in such a way that the original usage takes on added dimensions in the later context. Also, the original usage is itself affected (in retrospect) by its new relationships to an expanded context ${ }^{6}$.

La unidad que se establece en un ciclo de relatos es una de tensión entre el relato individual y el resto del texto. Ingram también señala que en un ciclo de relatos cada núcleo que forma el ciclo debe manifestar su independencia del resto, es decir, debe poder leerse por sí mismo como se leería un relato cualquiera. La diferencia entre un ciclo de relatos y una colección de cuentos sueltos no está en el carácter de los núcleos independientes, sino en las relaciones que se establecen entre los núcleos a través del mecanismo del "recurrent development". Por otra parte, la diferencia entro un ciclo de relatos y una novela yace en la manera en que las unidades de una novela se relacionan unas a otras mediante un principio causal y evolutivo, asi como a través de personajes que cambian en relación a la trama que se desarrolla ante ellos.

Los hallazgos y las conclusiones de Ingram con respecto a los ciclos de relatos y a los patrones estéticos que los gobiernan, tienen importantes reper. cusiones para el enfoque o lectura alternativa que aqui se propone, ya que al aplicar el principio de "desarrollo y repetición" a TTT las objeciones y los problemas que presenta como novela dejan de existir. Siguiendo el factor unitivo que ofrecen los relatos de los narradores en primera persona, se analizaran aquí los diferentes núcleos de significado señalados en nuestro esquema, primero en su valor intrínseco y después en sus relaciones con el resto del texto.

El primer núcleo comprende las secciones tituladas "Prólogo" y "Los debutantes", las cuales poseen narradores muy diversos que contribuyen a la creación del ambiente y presentan la temática que establece los nexos más importantes entre los otros núcleos del ciclo. La acción del "Prólogo" toma lugar en Tropicana ("el cabaret más famoso del mundo") ${ }^{7}$ y consiste en una serie de presentaciones hechas por un maestro de ceremonias al público en general. A pesar de que el contenido de la sección es sencillo y su objetivo principal es el de incorporarnos al ambiente de la vida nocturna de los clubes habaneros, en este preludio bilingüe las presentaciones de los diferentes personajes poseen un carácter incompleto y en contradicción a la idea tradicional del prólogo.

Otro problema que el contenido de este exordio subraya es el de la cronología de los hechos dentro de TTT. La noche de Tropicana con su locuaz maestro de ceremonias se recuerda en las narraciones de Códac ${ }^{8}$, de Mr.

\footnotetext{
6 Ingram, 19.

${ }^{7}$ Guillermo Cabrera Infante, Tres tristes tigres, 2da ed. (Barcelona: Scix Barral, 1967).

${ }^{8}$ Códac vuelve a referirse a la noche de Tropicana lo cual sugiere que la historia de La

Estrella ocurrió en un tiempo anterior al "Prólogo", 276-277.
} 
Campbell, y de Beba Longoria así como por Silvestre y Cué en la larga conversación de "Bachata", lo cual dificulta saber cuándo y en qué orden ocurren todos estos relatos. La cronología en TTT es confusa y deja no pocos cabos sueltos. Sin embargo, se pueden distinguir tres tiempos principales en el texto el pasado de "Los debutantes" (antecedentes inmediatos y recuerdos infantiles de algunos de los narradores principales, así como el de las dos narraciones de Códac) el presente de "Seseribó", "Casa de los espejos", y "Bachata"; y el no muy lejano futuro de las once viñetas narradas por Laura. Tales viñetas pueden ser consideradas el 'futuro' del ciclo ya que en "Bachata" Silvestre anuncia a Cué sus próximo matrimonio con Laura, también mencionado en una de las once viñetas.

Esta fragmentación temporal es fundamental para el estudio estructural de una novela; pierde importancia cuando se lee a TT'T como un ciclo de relatos. La cronología en un ciclo no es evolutiva sino significativa. En TTT la época en que ocurren todos los núcleos, es decir La Habana de los años 1958-1959, es básica para la comprensión de lo relatado. Sin embargo, la falta de exactitud en la cronología de los variados relatos del texto, su ambigüedad temporal y sus frecuentes contradicciones, son de poca importancia al concebir a TTT como un ciclo de relatos. Las observaciones de Ingram corroboran a este importante aspecto de todo ciclo ya que, para Ingram, el tiempo en un ciclo funciona de una manera repetitiva que sirve para asociar una situación con otra ${ }^{10}$.

Igual interés asociativo se percibe en la sección titulada "Los debutantes", la cual continúa presentando al resto de los narradores del texto, y junto con el "Prólogo", podría considerarse su verdadera introducción. En esta sección tan diversa es de interés analizar las tres viñetas del grupo femenino, ya que tratan sobre los cambios que han sufrido las vidas de estas tres mujeres al trasladarse ellas a la ciudad. Magalena, Livia y Beba aparecen y reaparecen una y otra vez en los diferentes relatos del ciclo, adoptando ellas un papel colectivo en el mismo, al representar el erotismo nocturno - tanto heterosexual como homosexual.

La cálida noche habanera, poblada de hombres y mujeres que quieren encontrar una aventura que les brinde la felicidad que no poseen en sus vidas diurnas, es de nuevo el trasfondo del primer relato del núcleo narrado por Códac titulado "Ella cantaba boleros". Esa la historia de Estrella Rodriguez, mujer cuyos orígenes y ambiciones son las mismas que se perciben en el personaje colectivo formado por Beba, Livia, Magalena y Cuba Venegas.

La historia de La Estrella se narra en ocho segmentos consecutivos que se interpolan a través del texto, todos bajo el mismo título de "Ella cantaba boleros". La trama del relato trata sobre los trabajos y tribulaciones que Códac, el narrador del cuento, experimenta para que el talento de La Estrella sea reconocido. Como medio de publicidad, Códac organiza una fiesta para dar a conocer al público a su Estrella, pero todo termina en fracaso. El relato concluye

\footnotetext{
${ }^{9}$ Rodríguez Monegal, 108.

${ }^{10}$ Ingram, 23-24.
} 
con la muerte de La Estrella en México, después de haber gozado un corto triunfo que en realidad no tuvo nada que ver con los esfuerzos y el interés de Códac.

Si la trama del relato es aparentemente simple, los mecanismos de su estructura interna hacen que una narración relativamente sencilla se complique en su lectura. El problema principal tiene que ver con el tiempo y su función con respecto a los hechos. Se pueden observar en el cuento tres niveles temporales: El 'presente' desde el cual Códac narra el relato de La Estrella; el tiempo 'recordado' que incluye el pasado de la vida de la cantante; y el tiempo 'soñado' que comprende los dos sueños de Códac que se relacionan directamente con la historia de La Estrella (pp. 160-161).

El hecho de que la estructura temporal del relato (y de otros en TTT) se encuentre fragmentada por el proceso del recuerdo se complica aún más con las digresiones que usualmente se relacionan al proceso de la memoria. Estos paréntesis, que muchas veces no tienen relación directa con el texto del relato, sirven para dilatar el tiempo recordado y contribuyen a crear el ambiente que sirve de tejido unitivo al ciclo. En "Ella cantaba" las digresiones corresponden a las recorridas de los clubes habaneros por Códac y a sus encuentros con las diferentes mujeres de la noche. Esta complicada estructura temporal permite que el relato se convierta en una doble historia: aquélla que Códac narra sobre La Estrella, y la historia del mismo Códac y de su vida nocturna ligada intimamente al ambiente de la noche habanera. Sin embargo, Códac, como la mayoria de los narradores del ciclo, evita a toda costa hablar de sí mismo.

La Estrella es una mujer definida en términos opuestos. La marcada diferencia entre su vida nocturna y su vida diurna es contada por Alex Bayer, personaje secundario, a quien Códac cede momentáneamente la narración. Bayer revela un aspecto muy importante en la vida de esta mujer, que es el de su triste realidad socioeconómica. Ella, como Cuba, Magalena y Beba, posee orígenes muy pobres y aunque trata de ol vidar su triste realidad con su música y su canción durante la noche, su vida diurna nunca la deja olvidar sus necesidades materiales. La Estrella, durante el dia, es criada de una pareja homosexual.

La revelación de Alex Bayer, además de añadir una nueva perspectiva a la situación, señala también el carácter contradictorio de la mujer. Además del factor económico; la Estrella es impulsada al éxito por su inmensa soledad, sentimiento compartido con Códac, el narrador de su historia.

Códac es un personaje muy alienado, quien busca alivio para su soledad, no en la fama, sino en el aturdimiento que le brinda el alcohol (p. 275). La noche y sus aventuras proporcionan a Códac el escape que él necesita de la inercia cotidiana. Aunque su verdadera vocación es la fotografía, su profesión no le provee una manera satisfactoria de expresar su arte. En el último fragmento del relato, ya después que La Estrella ha muerto, Códac continúa buscando y 
admirando la esencia de la autenticidad en la música" de "dos negritas lindas que cantan sin acompañamiento ..." (p. 287). Las Capellas, como La Estrella, son la perduración de esta manera de cantar, sin afeites y sin otra música que no sea la de sus cuerdas vocales, único aliciente al vacío en la vida del fotógrafo.

La soledad y la falta de propósito en la vida de los protagonistas se expresa artisticamente mediante las metáforas que Códac utiliza en su narración. La Habana se convierte en una pecera y las mujeres, como Irenita y Cuba, se transforman en peces de variados tamaños y colores (p. 169, 273). Tal elaboración no es sólo importante a la estructura intrínseca del cuento otorgándole su unidad, sino que también se convierte en un nexo que une a este núcleo con otros en el ciclo, convirtiéndose tales metáforas en una eficaz manera de describir el movimiento incansable y frenético de las calles habaneras. (En "Bachata", Silvestre se encuentra con una pecera en uno de los bares que él y Cué visitan la cual le provoca asociaciones muy similares a las observadas en este cuento).

De la misma manera que el uso de imágenes marítimas ofrece unidad intrínseca y extrínseca al ciclo, existen frases que ocurren como "leit motifs" en otras partes del texto, utilizadas no de una manera evolutiva, sino con un nuevo significado. La frase utilizada por Códac para describir a Alex Bayer ("En cada. actor hay escondido una actriz") posee un significado evidente dentro del relato ya que Códac nos habla abiertamente de la vida de Alex Bayer y de sus homosexualidad. Esta frase reaparecerá en "Bachata", esta vez en boca de Silvestre, para describir a Cué, el íntimo amigo de Silvestre. El proceso de usar frases o repetir imágenes a través del ciclo de una manera asociativa y no evolutiva es la esencia de lo que Ingram llama el principio del "recurrent development". El hecho de que esta frase se utilice en situaciones tan diversas hace posible que el lector asocie ciertas características de la personalidad de Bayer a la descripción que Silvestre hace de su amigo Cué.

"Ella caitaba boleros" es de gran importancia al ciclo de TTT, por varias razones. Desde el punto de vista genérico se sabe que éste fue en realidad el germen de todo el texto, dado que de este largo cuento se originó el resto de la narración que hoy se conoce por TTT ${ }^{12}$. Por otra parte, el hecho de que un cuento tan conciso y compacto se encuentre fragmentado e interpolado a través de casi trescientas páginas de texto indica varios problemas y posibilidades. Tal fragmentación ocasiona dificultades para aquellos críticos que insisten en la lógica evolutiva de TTT, es decir en sus características como novela. Algunos han tratado de encontrar nexos entıe las viñetas de Laura y los segmentos de "Ella cantaba" dado que, en muchos casos, ambos aparecen en yuxtapuestos ${ }^{13}$.

\footnotetext{
${ }^{11}$ Raymond D. Souza, Major Cuban Novelists (Columbia: University of Missouri Press, 1976) 85.

${ }^{12}$ Danubio Torres Fierro, "Entrevista con Guillermo Cabrera Infante", Vuella, 1 (octubre 1977): 23.

${ }_{13}$ William L. Siemens, Guillermo Cabrera Infante: Language and Creativity, Diss. (Kansas, 1972) 179.
} 
Sin embargo, la interpretación de $T T T$ como ciclo de relatos permite admitir algo inaceptable desde el punto de vista novelístico al concluir que "Ella cantaba boleros" constituye un relato independiente dentro del texto cuya fragmentación e interpolación obedecen antes que nada al deseo autorial de expresar a través dé la estructura externa del texto su visión existencial: "No hay voluntad de forma en mí, ni en mi método ni en mi vida. Más bien creo en el caos concéntriço"14.

De la misma manera, las tres secciones dedicadas al personaje de Bustrófedon pueden ser consideradas como una unidad de significado independiente. El relato de Bustrófedon se presenta en tres segmentos, uno a continuación del otro y cada uno con título independiente y distinto. "Rompecabezas" relata anécdotas sobre Bustro aún vivo mientras se divierte con sus amigos en los restaurantes y bares de La Habana; "La muerte de Trotsky referida por varios autores cubanos años después -o antes," consiste en siete parodias relatadas por Bustro y grabadas por Códac. El objeto de ataque de éstas es ahora el estilo literario de siete escritores cubanos. "Algunas revelaciones", la tercera sección, es también parte de la 'obra' de Bustro, esta vez escrita y no grabada. Esta consiste en una larga lista de nombres de personajes famosos que, en muchos casos, deriva su humor implícito de su lectura oral, o de la impresión visual que producen los nombres en la página impresa. No obstante, se debe advertir que, desde el punto de vista genérico, sería demasiado ambicioso llamar a estas secciones un 'relato'. En efecto, su contenido no posee un desarrollo definitivo como la historia de La Estrella. Sin embargo, este núcleo de apariencia fragmentaria, posee cierta unidad y se asemeja a una oración funeral o encomio a un personaje ya desaparecido. En "Rompecabezas" se relatan las anécdotas de un personaje que ya no vive; en "La muerte de Trotsky" el homenaje es póstumo; y en "Revelaciones" se recuerdan las ideas del fallecido.

En cuanto al desarrollo de los personajes, aunque a Bustrófedon se le describe físicamente, su personalidad y psicología quedan reducidas a sólo un aspecto: su facilidad para inventar y jugar con el lenguaje y su casi obsesión con todas las formas lingüísticas. Bustrófedon se convierte más bien en el portavoz de una idea o filosofía literaria que más tarde será llevada a cabo en otras obras del autor, especialmente en su libro titulado Exorcismos de esti(l)o.

Si Bustrófedon queda sumido en una profunda abstracción, Códac humaniza al relato al expresar su impotencia ante estas muertes que le ha tocado narrar. En la meditación de Códac, hay una queja en la que abundan matices filosóficos. Hay también cierta melancolía ar te el pensamiento de la muerte que no perdona a nadie, pero hay sobre todo furia porque han muerto sus amigos, para él genios, uno de la música (o el canto), el otro de la palabra hablada y su potencial creativo. Códac recuerda con gran nostalgia y tristeza los buenos

${ }^{14}$ Guillermo Cabrera Infante, carta. 
tiempos que él y su grupo de amigos (Silvestre, Cué y Rine) pasaron con Bustrófedon e insiste en su incapacidad para ser verosímil en la narración de los hechos: "soy malo conservador de las palabras cuando no tienen directamente que ver con la foto" .... (p. 223). Códac, como intérprete, sólo puede intentar "atrapar la voz humana al vuelo" y se frustra ante su incapacidad para darnos una versión más fiel del talento oral de Bustro.

El núcleo narrado por Códac es uno de los más importantes dentro del cicio dado que a él le toca narrar las historias de los personajes que representan los ideales en los diferentes cuentos. La presencia de estos dos personajes se percibe a través de todas las otras narraciones. En el caso de Bustro, su nombre y su memoria son evocados en los núcleos de Silvestre, Cué, y Eribó, quienes nunca lo cesan de admirar, mientras que en el caso de La Estrella, aunque nunca se menciona su nombre, los valores que ella simboliza se convierten en lo único positivo y puro en la vida de narradores como Eribó, el narrador del tercer núcleo del ciclo.

Eribó, en contraste con Códac, no narra la historia de otros personajes, sino que es protagonista de su propia narrativa. En el núcleo de Eribó se encierran dos segmentos: el primero pertenece a "Los debutantes" y relata como Eribó, dibujante, comercial, va a ver a su jefe, Solaún, (ya dado a conocer en el Prólogo) para solicitar un aumento de sueldo. El segundo segmento toma lugar años más tarde y presenta cómo las ambiciones amorosas del narrador son frustradas por su raza y su clase social.

Como en el caso de "Ella cantaba", la estructura interna del primer segmento se encuentra ligada al proceso del recuerdo. El cuento se narra como una memoria dentro de la cual existen tres secuencias temporales que forman una estructura circular. La trama comienza con la conversación inicial de Eribó con Solaún; pasa a la conversación, unos minutos antes, de Eribó con Yosi, la recepcionista; continúa con los antecedentes de Eribó los meses inmediatos a la visita, para terminar con el diálogo inicial del protagonista con Solaún.

A pesar de la fragmentación temporal, el cuento posee gran unidad que se logra a través de la elaboración artística de las imágenes acuáticas, factor que se observó anteriormente en la narración de Códac. La litografía que cuelga de la pared en la oficina de Solaún adquiere valores simbólicos que le otorgan unidad al cuento. Es ésta una pintura donde los pescadores se sienten amenazados por los tiburones, y expresa a su vez el acosamiento a que Eribó se siente sometido por Solaún. Las alusiones a la homosexualidad de los pescadores, (la palabra "buga" es sinónimo de homosexual, en el dialecto cubano) son símbolo de la ambigüedad y la falta de definición profesional en la carrera del narrador: "Tampoco era un artista ni un artesano. Era un profesional ... y me hallaba refugiado en esa tierra de nadie, en el foso que era mi oficio del siglo XX ...." (pp. 47-48). Eribó está castrado por su situación económica, un hombre que ha prostituido su verdadera vocación artística por el dibujo comercial encontrándose a merced de ricos potentados como Solaún. Al igual que La 
Estrella, Eribó tiene que afrontar una vida diaria llena de trabajos y tribulaciones y, como ella, o tal vez más que ella, él experimenta la frustración profesional causada por su situación económica y trata de evadir su triste realidad mediante aventuras como las narradas en "Seseribó".

"Seseribó" consta de siete partes de numeración consecutiva sin contar la leyenda afrocubana del principio ${ }^{15}$, la que sirve de prólogo artístico a la trama principal del relato. Este preludio anuncia, de una manera simbólica, la historia de una seducción y al mismo tiempo crea un ambiente donde la música auténtica y primitiva posee gran importancia.

El relato que sigue a este prólogo narra como Eribó conoce a Vivian, los furtivos encuentros que tienen y, finalmente, el fracaso de la relación que nunca llega a realizarse. Dentro de la trama se encuentran interpoladas largas divagaciones acerca de la música así como sobre los amigos de Eribó: Cuba Venegas y el dúo amistoso formado por Silvestre y Cué. La cronologia, como en el relato anterior, se encuentra alterada y debe ser leída de la siguiente manera: I, III, IV, II, V, VI, VII. Si el relato que sobresale en las secciones es la historia de Eribó y Vivian, los otros subrelatos dentro de la narración principal son también significativos al explicar los sentimientos de Eribó hacia Cuba Venegas y Arsenio Cué, de gran importancia al contexto total del ciclo que es TTT.

El fracaso entre Eribó y Vivian sirve para subrayar las irremediables diferencias entre clases y razas distintas al mismo tiempo que el dúo Silvestre/ Cué añade otra perspectiva a la historia. La intimidad que los dos amigos disfrutan hace sentir a Eribó fuera del 'juego' exclusivo que ellos parecen gozar. Sobre todo, la personalidad de Cué contraria a Eribó y hace que sus pensamientos divaguen hacia otras ocasiones en que Eribó recuerda el ridículo hecho por Cué a causa de sus alardes de cultura, como el día que el chofer de la máquina de alquiler tiene que corregir a Cué sobre la música que se oía por el radio: "Caballeros, ni Jáiden ni Jándel. Es Mósar" (p. 107). Estos incidentes que sólo parecen servir para romper la unidad del relato de Vivian y Eribó son importantes desde el punto de vista del funcionamiento del "recurrent development" del ciclo. Más tarde, en "Bachata", otra equivocación de Cué volverá a señalar este mismo aspecto de su personalidad.

Como en el caso de Eribó, el cuarto núcleo del ciclo narrado por Cué consta de dos segmentos. Uno es el pasado inmediato que comprende su llegada a la Habana procedente de la provincia y el otro, titulado "Casa de los espejos", se localiza en el 'presente' del ciclo.

La situación de Cué en el cuento inicial (que también forma parte de "Los debutantes") es aún más desesperada que la de Eribó, dado que Cué necesita trabajar para poder alimentarse. La trama del cuento narra cómo Cué va a pedir ayuda a cierto personaje de la televisión habanera que puede ayudarle a obtener empleo. Se relata entonces un episodio en la frustrada vida de otro artista, esta vez un escritor.

${ }^{15}$ "Rito de Sekany Ecue". Aqui Cabrera Infante modifica una de las creaciones de Lydia Cabrera, conocida folklorista cubana y amiga del autor. 
El cuento se encuentra estructurado en torno al motivo del hambre que sufre Cué el cual funciona en un doble nivel. Temáticamente, el hambre de Cué representa las vicisitudes que sufren los pobres cuando llegan de las provincias a la capital buscando la solución a sus problemas económicos y sociales. Artísticamente, el hambre funciona en la historia para al terar las percepciones de Cué y darnos, como lectores, una visión modificada de la realidad. En medio de su crisis física, Cué es incapaz de evaluar su propia situación.

La historia termina de una manera ambigua. No se sabe si Cué muere víctima de los tiros del magnate poderoso, o si simplemente se desmaya por la debilidad y el hambre que tiene. En "Bachata", Cué nos da otra conclusión para. el relato, asegurando que todo lo que sucedió entonces fue que se desmayó. Cué confirma que no murió, que los disparos fueron salvas, y que todo lo que había hecho era desmayarse y alucinar a causa del hambre y del nerviosismo que tenía.

La conclusión que aparece en "Bachata" proporciona otra perspectiva de los hechos relatados, perspectiva que no es esencial al éxito y al interés del cuento tal y como ocurre en la sección de "Los debutantes". Este es en sí una unidad independiente que deriva su éxito y su tensión de la ambigüedad en que deja al lector. De esta manera, la página en negro ${ }^{16}$, o sea el 'pozo' en que Cué cree haber caído al final de la historia, es la representación visual de este desmayo que bien puede haber sido la muerte espiritual del protagonista.

Pero si la necesidad y el hambre acosan a Cué durante su llegada a la capital, pronto su talento lo ayuda a superarlas. En "Casa de los espejos", episodio que ocurre años más tarde, Cué ya se encuentra establecido y bien relacionado en la metrópolis. La trama del cuento presenta, como se ha visto en las otras narrativas del ciclo, una fragmentación temporal. Existen aquí dos tiempos: el presente de las aventuras de Silvestre y Cué con las vedettes Mirtila y Livia, y el pasado que narra el idilio entre Laura y Cué. Por primera vez en el ciclo se dan fechas exactas: el presente se fija en 1958; la historia de Cué y Laura toma lugar un año antes, o sea en 1957.

Las noches de Cué se convierten todas en una misma noche, el futuro equivale al presente, todo manifiesta inmovilidad e inercia (p. 144). Este sentimiento se expresa al final del episodio cuando Cué baja las escaleras de la casa de Livia y Mirtila. Su descenso adquiere cierto valor simbólico que tiene nexos directos con el pozo negro en el que cayó física y simbólicamente al llegar a La Habana: "un pie en el vértigo, otro pie en el abismo, otro pie en la nada" (p. 156).

El vacío existencial que le proporciona su vida nocturna no sólo se comunica a través del personaje de Cué sino también mediante las mujeres que él y Silvestre encuentran en sus correrías, como Livia y Mirtila. La noche se vuelve

${ }^{16}$ La página en negro fue omitida de las ediciones de TTT posteriores a 1970 por razones desconocidas. 
el manto, la cubierta que esconde la realidad y la juventud que se va y con ella la pérdida de la apariencia atrayente de estas dos mujeres. Ellas son descritas por Cué con hastío y tristeza. No sólo representan la falsedad y la hipocresía ${ }^{17}$, sino que también encarnan la decadencia en progresión, resul tado de la vida que llevan en esta engañosa metrópolis. Si las dos mujeres fueron una vez atractivas y sensuales ahora se encuentran en un estado que las obliga a salir sólo "de noche y espesamente maquilladas" (p. 154).

El próximo núcleo, narrado por Silvestre, elabora de nuevo la perspectiva social de Cué así como su enigmática personalidad en un cuento que aparece en "Los debutantes" y en la larga y famosa sección titulada "Bachata". El cuento, como los cuentos de Eribó y Cué, relata un episodio del pasado, esta vez más distante y que se remonta a la infancia de Silvestre. "Bachata" no contiene una sola acción sino que el contenido de la sección es de una naturaleza aclaratoria que se asemeja a una "glosa"18 es decir una narrativa que funciona como explicación o comentario al resto del ciclo.

La trama del episodio de "Los debutantes" narra cómo Silvestre y su hermano son testigos de una muerte a sangre fría en una calle de su pueblo natal, un día en que los dos se encaminan al cine. Existen en el relato dos importantes dimensiones temáticas. La primera es esencialmente social y muestra la pobreza y la violencia del medio en que se educan los provincianos. La segunda dimensión de la historia tiene que ver con el tema del arte, o sea con la especial predilección que Silvestre siente hacia el cine ${ }^{19}$. Para el Silvestre adolescente, el cine representa: "la aventura, la libertad y el sueño" (p. 40), una forma de arte superior inclusive a la literatura. En "Bachata", Silvestre narra. otro episodio similar que ilustra los mismos temas, sólo que ahora Silvestre se encamina al cine con su padre cuando les toca a ambos presenciar otro asesinato. De una manera muy quijotesca ${ }^{20}$, el cine se vuelve la verdadera realidad para Silvestre o, por lo menos, una realidad preferible a la que tiene que afrontar cada dia.

"Bachata" es el núcleo más complicado del ciclo al poner en tela de juicio algunas de las asunciones que se han hecho aquí sobre la capacidad que cada

\footnotetext{
${ }^{17} \mathrm{El}$ mejor tratamiento del tema lo hacen Beatriz Borges y Flora Su ssekind, "Tres tristes tigres: un blasfemo jogo de espelhos", José 11 (1976): 39-44.

${ }_{18}$ Una glosa es una "explicación o comento de un texto oscuro o difícil de entender". Existen varios tipos de glosas entre las cuales se encuentran las bíblicas, las de tipo legal, etc. Se debe notar que dicho vocablo también tiene una significación musical ya que "modernamente se llama glosa al desarrollo de variaciones sobre un tema y también a una especie de vocalización". Este último significado es de interés si se considera que el mismo Cabrera Infante se refiere a TTT , en una de sus cartas, como "rapsodia en prosa". Véase: "Glosa", Enciclopédia Universal Mustrada, 1925 ed.

${ }^{19}$ Phyllis Mitchell, "The reel against the real: Cinema in the novels of Guillermo Cabrera Infante and Manuel Puig", Latin American Literary Review, 6 (FallWinter, 1977) 2230.

${ }^{20}$ Juan Goytisolo, "Lectura cervantina de $T T T$, , Revista Iberoamericana, 42 (1976): 119.
} 
núcleo posee de mantener su independencia como relato y de hallarse, al mismo tiempo, relacionado con el relato del texto a través del principio dinámico del "recurrent development". En "Bachata" no existe una sola acción, sino que el contenido posee un carácter muy diverso que tiene que ver con ideas que expresan la manera en que los personajes conciben sus vidas: "inercia y propaganda y, en algunos casos, tanto por ciento. Esa es la vida" (p. 342).

La estructura externa de "Bachata" se compone de veintidós segmentos numerados consecutivamente que, sin embargo, no garantizan una transición lógico-causal. Asimismo, la estructura interna del núcleo se rige y se guía mediante un proceso asociativo e imita fielmente la lógica de la conversación.

Silvestre resume la base estructural del segmento afirmando que "viajar con Cué es hablar, pensar y asociar" (p. 293). En efecto, los tres elementos serán de gran importancia para comprender la lógica del núcleo.

La conversación es la acción principal de tan larga y abarcadora sección, la cual dura toda una noche cuando Silvestre y Cué se dedican a recorrer las calles habaneras en busca de divertimiento. La vida se les presenta confusa y deprimente. En efecto, la única solución a esta realización es vivir el momento, el sentirlo intensamente para así poder conquistar la finitud temporal. La velocidad es lo que sirve para unir, a través de la sensación del vértigo, al tiempo y al espacio y darles el ilusorio y temporal triunfo de conquistar a la nada y a la muerte, es decir a sus vidas indolentes: "buscaba el tiempo en el espacio y no otra cosa que una búsqueda eran nuestros viajes continuos, interminables, un solo viaje infinito por el Malecón" (p. 269).

Por otra parte, el verdadero escape que este dúo amistoso encuentra se manifiesta en el mundo cul tural; en el misterio del arte. Silvestre y Cué llegaron a La Habana con el deseo de convertirse en escritores. Silvestre lo consiguió mientras que Cué terminó, obligado por su necesidad, convirtiéndose en actor de televisión, frustrando así su verdadera vocación (p. 424). Silvestre, en su papel de escritor, alude a la presencia física en el texto de ciertos núcleos del ciclo como si él en realidad estuviese escribiendo su propio libro. Uno de estos núcleos es la viñeta narrada por la mujer anónima (octavo núcleo en nuestro esquema) incidente que Silvestre hace aparecer como obra de su propia pluma: "y le pedí papel y lápiz ..., regresé y alcancé un pedazo del discurso"(pp. 299-300). El hecho de que el segmento se comente como la obra del propio Silvestre establece una dependencia entre "Bachata" y esta viñeta final.

De la misma manera, Silvestre está consciente de hacer literatura cuando se refiere a la sección titulada "Los visitantes" (sexto núcleo). Cabrera Infante, ahora como personaje dentro del texto, ordena a Silvestre que revise la mala traducción que Rine había hecho del cuento. Se explica así que existan dos segmentos con títulos y tramas muy similares: el primero es la traducción de Silvestre, y el segundo es la traducción "pésima" de Rine, ambas, versiones de un cuento escrito en inglés por un autor americanollamado Mr. Campbell, quien se encontraba en Tropicana la noche de las presentaciones (p. 438). 
La infidelidad de toda traducción es un tema recurrente en los variados núcleos del ciclo. Ya desde el comienzo, el monólogo bilingüe del maestro de ceremonias subraya la falta de equivalencia en su traducción oral, su poca aptitud para traducir de un idioma a otro. Asimismo, la última frase en "Bachata" afirma el carácter traicionero de toda traducción, sujeto comentado por Cué y Silvestre a través de esta larga conversación.

Otro tipo de dependencia textual en "Bachata" tiene que ver con el cuento de Cué, el cual aparece en la sección titulada "Los debutantes" (tercer núcleo). Silvestre ahora cede la narración a su amigo quien 'añade' otro final al cuento que él antes habia narrado. Al oír el segundo final, Silvestre cuestiona a su amigo como si él ahora asumiera el papel del lector y quisiera eliminar las ambigüedades que la primera versión le había presentado: “¿Pero, las balas? ¿Por qué no te moriste?" (p. 424).

"Bachata" comenta al ciclo y trae a colación el carácter de escritura de esta red de cuentos y de viñetas. En efecto, a través de las referencias mencionadas, "Bachata" se mantiene dependiente del texto convirtiéndose en una especie de 'glosa' destinada a aclarar las partes oscuras del texto, siéndole imposible existir fuera de él como relato autónomo. Este hecho se complica aún más cuando se piensa en las referencias que existen en la conversación sobre ciertos hilos que se relacionan con "Seseribó" y "Casa de los espejos", así como con la repetición de frases o situaciones que ya se han visto en otros núcleos del texto.

De mayor importancia son los nexos que unen a "Casa de los espejos" y a "Bachata" los cuales sugieren cierta rivalidad entre Silvestre y Cué. El nombre de Laura se menciona en esta larga conversación, sólo que esta vez, en relación a Silvestre, quien anuncia aquí su futuro matrimonio con ella. Cué, como buen actor, trata de ocultar sus sentimientos y de no reaccionar ante la noticia que Silvestre le acaba de dar. La boda de Laura y Silvestre de seguro afectará la amistad entre los dos amigos al convertirse este matrimonio en una especie de traición a Cué. Laura, afecta la vida de ambos narradores aunque, en consonancia con el carácter conversacional de "Bachata", este importante aspecto nunca se profundiza:

Los nexos que unen a "Bachata" con el resto del textos nexos no son causales. Sí, es verdad que en "Bachata" se discuten hechos que se relacionan a la trama de otros núcleos, pero la discusión se limita a mencionar, no a desarrollar los hechos como se esperaría de una novela convencional. El uso de frases y de situaciones que ya se han visto en los otros núcleos establecen un sistema de ecos que obedecen al principio conectivo del "recurrent development". Silvestre, en su narración, utiliza principios descriptivos ya observados en otros núcleos del ciclo. Como Códac y Eribó, él describe a los habitantes de la ciudad como "la fauna del zoológico nocturno" (p. 324). Más tarde, en uno de los bares que ellos visitan, se encuentra con una pecera real que le recuerda la claustrofobia provocada por sus correrías nocturnas (p. 336). 
La resonancia con el resto del texto es otras veces más directa, como cuando Silvestre utiliza la frase "en cada actor hay escondido una actriz" para describir a Cué (pp. 304, 308, 406) siendo ésta la misma que Códac había utilizado para describir a Alex Bayer. El significado del apelativo en "Bachata" nunca queda claro aunque su frecuente uso hace surgir dudas sobre la identidad sexual del enigmático Cué.

De una manera muy similar, en "Bachata" surgen situaciones que establecen paralelas con otras que ya se han visto dentro del texto. El episodio narrado por Eribó en "Seseribó", encuentra en "Bachata" varios ecos que parecen volver a subrayar la pedantería cultural de Cué. Ahora, en vez de ser corregido por el taxista, Cué es enmendado por el locutor de la estación radial que escuchaban en aquel momento. La frase "Bach/Vivaldi" se repite aquí (pp. $309,363)$ y actúa como un leit motif que recuerda que Cué, a pesar de su erudición, es también capaz de cometer errores.

"Bachata", como se ha demostrado, es un intento de dar otras perspectivas a muchos de los relatos que forman el ciclo comentando estas partes del texto y ofreciéndonos nuevas formas de interpretación para las mismas. El hecho de que "Bachata" sea, dada su naturaleza, dependiente del resto del texto no quiere decir que el resto del tex to dependa de "Bachata". Cada núcleo en el ciclo forma una unidad autónoma, como se ha venido probando, y como lo demuestra el siguiente análișis de "Los visitantes", sexto núcleo del ciclo.

"Los visitantes" es de carácter peculiar al presentarse como dos versiones de un mismo cuento. La primera se titula "Historia de un bastón y algunos reparos de Mrs. Campbell" (pp. 170-184) y la segunda "El cuento de un bastón seguido de vaya qué correcciones de la Sra. Campbell" (pp. 185-203). El núcleo posee dos dimensiones: la primera se puede apreciar si se analiza este segmento como cuento independiente del ciclo (cualquiera de las dos versiones); la segunda, como se acaba de demostrar, sólo se puede percibir en relación a "Bachata", en donde se explica por quẹ existen en el texto dos versiones de una misma historia.

El relato narra cómo un matrimonio de turistas llega a La Habana con el objeto de pasar un fin de semana en la ciudad. Entre los objetos de interés que la pareja obtiene como recuerdo se encuentra un bastón que parece fascinar a Mr. Campbell. Un día, mientras recorre la ciudad, Mr. Campbell se da cuenta de que ha extraviado su bastón, al mismo tiempo que descubre a un mendigo con un bastón idéntico al que ha perdido. Mr. Campbell reclama su bastón al mendigo, éste se resiste y pronto se forma una turba alrededor de ellos. Un policía intenta solucionar la situación al hacer que el mendigo devuelva el bastón a Mr. Campbell. La pareja recibe una gran sorpresa cuando regresan al hotel y encuentran que el verdadero bastón todavía está en el cuarto y que ellos son ahora los propietarios de dos bastones.

La acción del relato se desarrolla en torno al tema del perspectivismo, es decir, la manera en que una misma realidad puede ser interpretada según el 
punto de vista del que la contempla. En primer lugar, y en relación con el resto del ciclo, tenemos a la valoración que Mr. y Mrs. Campbell nos dan de la ciudad habanera. La impresión que los dos turistas reciben de la ciudad contrasta con la de los otros narradores del ciclo: los que viven esa realidad que, para los Campbell, resulta exótica e interesante. El perspectivismo también se expresa mediante la estructura bipartita de cada versión: 1) los hechos narrados por Mr. Campbell, y 2) los reparos que le hace a la mujer. De este modo, el lector no recibe una versión objetiva de los hechos _. dato que podría sugerir otro intento de presentar una realidad cambiante que desafíe todo esteticismo.

El núcleo séptimo es uno de los más crípticos del ciclo, dado que la identidad de la narradora nunca se revela. Sin embargo, los críticos, ayudados por comentarios autoriales, han llegado al consenso de que la narradora es Laura Díaz, la mujer con quien Silvestre piensa casarse en "Bachata" (p. 434). De esta manera la historia contada por Laura a su psiquiatra se narra en un tiempo futuro a "Bachata", dado que en la viñeta "Primera" Laura afirma ya estar casada con un escritor.

Además de las once viñetas que narran las conversaciones de esta mujer con un psiquiatra, el núcleo consta de un corto relato infantil que pertenece a la sección introductora de "Los debutantes". El relato, narrado desde el punto de vista de una niña, refiere cómo ella y su amiguita espían a una pareja de novios y cómo lo que ven las excita a su vez. Más tarde, las dos niñas se convierten en la sensación del pueblo deleitándose al contar las "cosas" que Petra y su novio se atrevian a hacer. Este erótico recuerdo infantil da muestras de la ignorancia pueblerina, de los chismes y de la vida cerrada del pueblo donde Laura pasó sus primeros años, y complementa al mismo tiempo la narración de la viñeta en la que las murmuraciones y los chismes de los pueblerinos adquieren un carácter despiadado y cruel (p. 447).

Las once viñetas numeradas cuentan otros episodios de la vida de Laura. Su infancia desdichada y violenta se mezcla con la pobreza de su adolescencia, con su temprana viudez que resulta en la pérdida de la custodia de su hijita, así como con los problemas que ahora tiene con su segundo marido (Silvestre). Sus sueños atormentados reflejan de qué manera los desafortunados hechos en su vida han terminado por alienarla de su propia circunstancia. El hecho de que la historia de Laura se encuentre interpolada a través del texto (de la misma manera que sucedió con la historia de La Estrella) ilustra de nuevo el deseo autorial de expresar, mediante la forma, la confusión y la angustia reflejadas en la triste historia de la mujer. La historia también apunta hacia el negro futuro que confrontan todos los protagonistas, e implica el profundo pesimismo con que el autor envisiona a sus personajes. Laura, comolos otros narradores en el texto, tuvo que vivir una época difícil y ahora sufre las consecuencias de su pasado.

El último núcleo consiste en sólo una viñeta, la cual de nuevo posee como tema lo irracional, sólo que esta vez la patología es radical. Bajo el título de "Epílogo" ella contradice, al igual que el "Prólogo" la idea tradicional que este 
concepto exige. Su significado con respecto al universo del ciclo es totalmente simbólico y de ahí su negro pesimismo. Se nota en esta viñeta anónima una urgencia y un deseo de cambio. Es ésta la queja de una mujer enloquecida ante el ambiente que la rodea. Se unen aquí por primera vez la falta de libertad política ("Que viene el mono con un cuchillo y me registra") (p. 451) con el caos existencial. La crisis de Laura se lleva a un extremo por una mujer que ha llegado al borde de la desesperanza y, por lo tanto, a la locura total: ella es la víctima suprema del efecto corruptor del medio en que le ha tocado vivir.

Esta lectura de TTT ha destacado en detalle las semejanzas temáticas entre las unidades del texto y el desarrollo dinámico de sus partes. Los nexos entre las diferentes partes del libro adquieren su significado esencial por medio de los temas elaboración artística, para demostrar el fuerte enlace de las dos vertientes en la obra cabreriana: la realidad social y la realidad artística.

La unidad principal de los núcleos del texto proviene del trasfondo realista que proporciona la ciudad de La Habana y la influencia que ella ejerce en los protagonistas de los variados episodios. Les ha tocado a ellos vivir en una época que posee cierta finalidad, porque La Habana de los años 50 era una Habana destinada a desaparecer. De ahí que todas las narraciones posean un tono nostálgico, dado que relatan episodios de un mundo a punto de extinguirse. Se vuelve entonces el libro, de apariencia tan frívola, en un documento sociológico de una época en la que una generación de provincianos se ven empujados por su pobreza hacia la metrópolis, y una vez alli se ven obligados a comprometer su integridad para sobrevivir al ambiente corruptor. Cada relato termina en una nota de melancolía y desesperación, cuando la búsqueda desenfrenada del placer se transforma en una actividad vacía y carente de objetivos. Tropicana, y los diferentes clubes se convierten en una manera más de escapar al caos y la confusión en la vida de los personajes. Sin embargo, la angustia existencial sentida por los protagonistas hace que TTT pase de la inmediatez de su contexto a un tono más universal ${ }^{21}$.

La vertiente artística hacia la que estos relatos apuntan también le confiere a TTT su integridad textual. Todos los protagonistas se encuentran relacionados con algún aspecto del arte: la fotografía, el cine, la pintura, la música y la literatura, $\mathrm{y}$ aunque algunos.han tenido que prostituir su verdadera vocación para sobrevivir otros, como La Estrella y Bustrófedon, son idealizados y admirados dentro del texto por su autenticidad y su talento.

El texto se convierte además en un 'homenaje a la literatura' con sus abundantes referencias a autores de todas nacionalidades y épocas, y ejemplifica con Silvestre el derecho de todo escritor a inventar su propia ficción. El arte, sea a través de la música de La Estrella o de la facilidad lingüistica de Bustrófedon, se convierte en lo único positivo y permanente ${ }^{22}$ dentro de un

21 John S. Brushwood, The Spanish American Novel: A Twenlielh Cenlury Survey (Austin and London: University of Texas Press; 1975) 292-296.

22 Souza, 85 . 
mundo que se desintegra paulatinamente. El lenguaje de TTT se halla también fuertemente ligado al tema de la creación. Este aspecto, citado frecuentemente por la crítica, se expresa no sólo a través de Bustrófedon sino mediante la cónstante experimentación lingüística en los diferentes episodios del ciclo. El lenguaje coloquial permite expresar las posibilidades que el lenguaje oral adquiere mediante la escritura; proceso que destaca las implicaciones visuales, fonéticas e intelectuales inherentes a todo vocablo. Como en Exorcismos, el lenguaje aquí también ilustra su potencial para ocultar cualquier tipo de realidad, tema importante en los núcleos del texto.

Vista como ciclo de relatos, la complicada estructura de TTT se hace más accesible. TTT es una creación artística que posee al mismo tiempo un significado particular ofrecido por cada núcleo y un significado total que se manifiesta mediante los nexos que los unen. La variedad de tramas en el ciclo representa la ambigüedad de la experiencia humana, dado que los valores humanos producen actitudes que son también ambivalentes. Por consiguiente, la falta de-personajes que se desarrollen de una manera novelística ilustra la confusión de estos seres ante una vida que se les presenta de sobremanera incierta.

El ciclo de cuentos, género común a la literatura actual ${ }^{23}$ representa dentro de la obra de Cabrera Infante una visión personal de géneros ya en existencia ${ }^{24}$ como lo son el cuento y la viñeta. Por otra parte, la aplicación del concepto de 'ciclo' a una de las 'novelas' de la nueva narrativa hispanoamericana posee repercusiones que van más allá de lo que se trata en este estudio e invita a la aplicación de los conceptos aquí expuestos a otras "antinovelas" " "metanovelas" que continúan intrigando a la crítica. Apunta esta exploración hacia otras avenidas de análisis para la compleja ficción de nuestro siglo.

${ }^{23}$ En el ya citado estudio, Ingram demuestra que obras como The Unvanquished de William Faulkner y Ein Hungerkünstler de Franz Kafka, entre otras, pueden ser mejor comprendidas dentro del concepto estructural de los "short story cycles".

${ }^{24}$ Alfred J. MacAdam, Modern Latin American Narratives: The Dreams of Reason (Chicago: The University of Chicago Press, 1977). MacAdams envisiona a T'T T como una versión de la sátira menipea en la que el texto se convierte en una metáfora de la realidad. 
